\title{
HaviStat@ v2.2: Application to estimate preference for habitat and resources
}

\author{
Javier A. Montenegro ${ }^{1 凶}$, Alberto Acosta ${ }^{2}$, James D. Reimer ${ }^{3}$
}

\begin{abstract}
HaviStatC v2.2 is available in Spanish and English. In this version reported errors and recommendations from v1.0 were fixed and implemented. HaviStat $(\mathrm{C}$ allows users to perform the necessary mathematical, statistical and graphical procedures required to preliminarily infer use, selection, and preference for habitat/resources, and to estimate the niche breadth of species. In this new version radial diagrams, 22 indexes and 3 confidence intervals for animal preference evaluation, and 8 indexes for niche breadth estimation are available.
\end{abstract}

Keywords: habitat; preference; HaviStatC; indexes; confidence intervals.

Edited by Luz Teresa Valderrama®

1. University of the Ryukyus, Graduate School of Engineering and Science, Marine Invertebrate Systematics and Ecology Laboratory. Nishihara, Okinawa, Japan. e-mail: havistat@gmail.com ; Tel: +81-98895-8542 ; Fax: +81-98-895-8576.

2. Pontifica Universidad Javeriana, Faculty of Science, Department of Biology, Unit of Ecology of Systematics, UNESIS. Bogota, Colombia.

3. University of the Ryukyus, Faculty of Science, Department of Biology, Chemistry \& Marine Sciences, Marine Invertebrate Systematics and Ecology Laboratory. Nishihara, Okinawa, Japan.

Received: 23-06-2014 Accepted: 25-07-2014

Published on line: 01-08-2014

Citation: Montenegro JA, Acosta A, Reimer JD (2014) HaviStatC v2.2: Application to estimate preference for habitat and resources. Universitas Scientiarum 19(3): 333-337 doi: 10.11144/Javeriana.SC19-3.haea

Funding: N/A

Electronic supplementary material: 1 (free program download instructions)

\section{Introduction}

Selection and preference for habitat/resources are topics of great importance in natural resource management and evolution. Patterns of habitat selection form an important base to study evolutionary processes as individuals able to select and use necessary resources will be also likely to have the highest fitness in between populations (Nielsen et al. 2013). The study of this topic also allows inference of ecological requirements, conditions and resources necessary for species' survival, development and reproduction, and helps to explain their abundance, distribution (Manly et al. 2002, Davis \& Stamps 2004), and how evolutionary strategies persist through time (Davis \& Stamps 2004). When habitat preference is analyzed by partitions of space (i.e. same habitat in different locations or sizes) and/or time (i.e. hours of the day, how many times 
per day, week) it is possible to find evidence to explain how species of the same guild or genus coexist and occupy niches that overlap in terms of resources and conditions (Vidus-Rosin et al. 2011).

Despite its importance the study of habitat preference is still controversial and difficult, primarily due to the dispersion of information in literature, and the large variety of mathematical and statistical methods developed. HaviStat $(\mathrm{C}$ was created to address this issue (Montenegro \& Acosta 2008) and is currently used by researchers from 40 different universities in 13 countries (e.g. Argentina, Spain, Ukraine, Brazil and México) as well as by undergraduate and graduate students. HaviStat $(\mathrm{C}$ aims to be a comprehensive compilation of simple mathematical models to evaluate animal selection/preference, rather than a program to incorporate the latest trends for the evaluation of animal behavior (i.e. mechanistic modeling), as many of these methods are currently considered computationally intensive, difficult and impractical for large datasets and which require considerable expertise to implement and interpret (Beyer et al. 2010). HaviStat $@$ compiles existing indexes and confidence intervals for evaluation of habitat preference and selection (for detailed information please see the reference section inside the program) in a practical way, but does not include probabilistic approaches such as those developed by Manly et al. (2002), Keating \& Cherry (2004), Cañadas et al. (2005), Aarts et al. (2008), Fukuda \& Hiramatsu (2008) and Lele (2009); or more complex models aiming to integrate animal movements and habitat preferences simultaneously as those presented by Rhodes et al. (2005), Christ (2008), Horne et al. (2008) and Fieberg (2010). However, HaviStatC allows scientists to efficiently screen large sets of data for any emerging biological pattern and to create bases for more extensive research or sophisticated modeling techniques.

\section{Methodology}

This application is the result of a wide literature review, where we have selected and organized the most important information on this topic. By using the reference section of the program, researchers will be able to understand and properly use the different indexes and confidence intervals implemented in this version, and get a solid understanding of the theoretical bases and experimental design to study this topic. The application is written in Visual Basic as macros designed to be compatible with Microsoft Office ExcelC 1997 or later, and works best over Microsoft Office ExcelC 2010 (OS Windows(C). The interface consists of seven sheets; Data, Breadth Indices, Preference Indices, Saved Indices, Graphics, References and Manuals. The page "Data" is the principal interface of the application, where all the mathematical and graphical analyses can be executed (Figure 1). For details of how to use each of the pages and their options please refer to the User's Manual inside the program. To execute the application it is necessary to allow the use of Macros inside the "HaviStatC v2.2" workbook by clicking "Enabling Contents" when the file is open. Additionally a PDF reader (e.g. Adobe) is required in order to access the references and manuals. The versions 1.0 and 2.2 of this software are available for free download (see Suppl. 1 for instructions) on the webpage <http:// miseryukyu.com/MISE\%40University_of_the_ Ryukyus/Data_sets.html $>$ or by request to the e-mail address<havistat@gmail.com>.

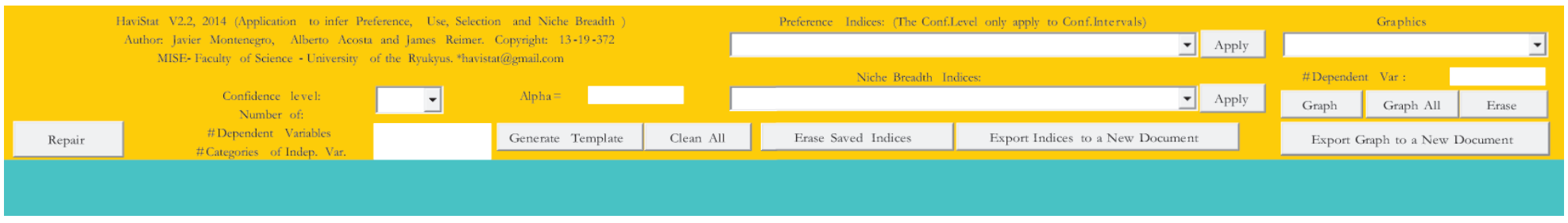

Fig. 1. "Data" sheet of HaviStat $@$ v2.2, the principal page of the application. 


\section{Results and Discussion}

HaviStat v2.2 interface and manuals are available in English and Spanish and new ways to estimate niche breadth and habitat/resources preference were implemented. Additionally, as requested by users of HaviStatC v1.0, in this new version confidence intervals show the expected use instead of the expected probability of use in the results matrix, and the explanations of the index and confidence intervals have been clarified. The graph sections can also be fully exported along with the data to new documents outside of the HaviStat $\mathrm{C}$ v2.2 workbook. The audiovisual manuals were eliminated in the second version, but a new and more concise manual with a remodeled and updated reference section is presented. The reference section includes direct links to the original information, and equations of each index are included in the application; and a new way to present data using radial graphs was also implemented.

The improvements in HaviStat v2.2 were performed with the aim to increase functionality. For example, the fact that the expected ratio of use is now shown in the output of the confidence intervals provides a better understanding of the colors code employed in the outputs for users. In this version all analyses can be fully exported outside the application, allowing users to process different datasets without altering results of previous analyses. Having radial diagrams as a graphical option allows users to compare and contrast for each habitat/resource, observed use and potential availability simultaneously for several species. Additionally, the implementation of this type of graphical analysis makes it possible to use HaviStatC to identify species potentially undergoing competition via exploitation or competitive coexistence processes by showing evidence on the tendencies of habitat selection/preference and niche differentiation between closely related or competing species (Figure 2).

HaviStat is particularly useful for scanning large datasets (test-proven with a matrix of $100 \times 100$, and theoretically as many cells and columns as Microsoft Excel(C) allows) to look for patterns of preference and selection. From this point researchers could incorporate more sophisticated analyses with software such as "R" (environment for statistical computing and graphics <http://www.r-project.org/>) or the package "adehabitat" (Calenge, 2006; <http://cran. univ-lyon1.fr/web/packages/adehabitat/>), which includes a basic Geographic Information System manager, and apply different methods for analyses of wildlife radio-tracking data.
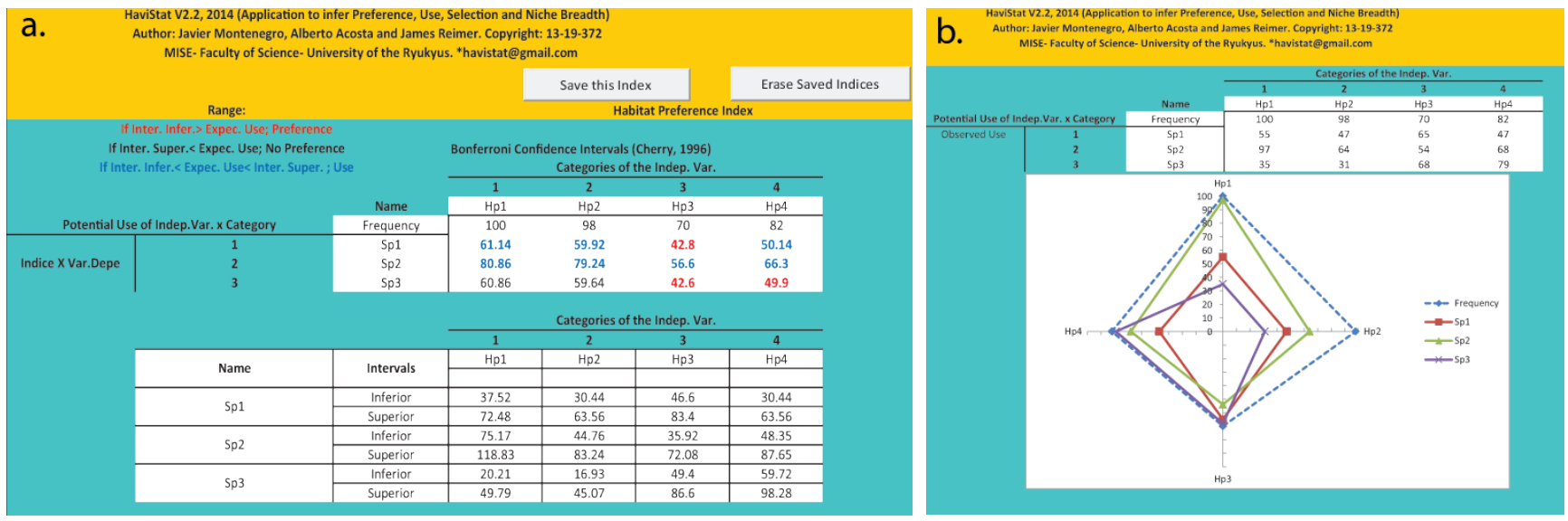

Fig. 2. Some of the new implementations for HaviStatC v2.2. a) Boferroni confidence intervals showing results interpretation in colors and the inferior and superior boundaries of the interval; b) Radial diagram simultaneously showing how different species use four categories of habitat. 


\section{Conclusion}

HaviStat $(\mathrm{C}$ v2.2 is freeware designed to perform basic analyses of niche breadth, habitat preference and use. The application includes 25 ways to evaluate animal preference, 22 indices and 3 confidence intervals, and 8 indices to evaluate niche breadth. This application compiles most of the indices in the literature, and it is also clear, specific, practical, and designed with a userfriendly interface. Furthermore, the software does not require installation, and includes literature and manuals to properly guide the user through the application. HaviStat $(\mathrm{C}$ represent a valuable tool for education and basic research of habitat selection/preferences rather than a platform for in-depth modeling of animal behavior. The advantages of this application over similar software are that it is free, does not require any programing skills, is implemented within a familiar environment (Microsoft Excel), was designed to be highly intuitive, and gives easy access to reference information.

\section{Acknowledgements}

The first author thanks users of HaviStat(C) v1.0 for examining an earlier version of the software and manual, and for supplying many useful comments.

\section{Conflict of Interest}

The authors declare that they have conflicts of interest, and for this reason the entire review process and approval of the paper was handled and edited by Luz Teresa Valderrama (co-editor).

\section{References}

Aarts G, MacKenzie M, McConnell B, Fedak M, Matthiopoulos J (2008) Estimating space-use and habitat preference from wildlife telemetry data. Ecography 31(1):140-160 doi: 10.1111/j.2007.0906-7590.05236.x

Beyer HL, Haydon DT, Morales JM, Frair JL, Hebblewhite M, et al. (2010) The interpretation of habitat preference metrics under use-availability designs. Pbilosophical Transactions of the Royal Society B: Biological Sciences 365(1550):2245-22544 doi: 10.1098/rstb.2010.0083

Calenge C (2006) The package adehabitat for the $R$ software: a tool for the analysis of space and habitat use by animals. Ecological Modelling 197: 516-519 doi: 10.1016/j.ecolmodel.2006.03.017
Cañadas A, Sagarminaga R, De Stephanis R, Urquiola E, Hammond PS (2005) Habitat preference modelling as a conservation tool: proposals for marine protected areas for cetaceans in southern Spanish waters. Aquatic Conservation: Marine and Freshwater Ecosystems 15(5):495521 doi: $10.1002 /$ aqc.689

Christ A, Ver Hoef J, Zimmerman DL (2008) An animal movement model incorporating home range and habitat selection. Environmental and Ecological Statistics 15:27-38 doi: 10.1007/s10651-007-0036-x

Davis JM, Stamps JA (2004) The effect of natal experience on habitat preferences. Trends in Ecology \& Evolution 19(8):411-416 doi: 10.1016/j.tree.2004.04.006

Fieberg J, Matthiopoulos J, Hebblewhite M, Boyce MS, Frair JL (2010) Correlation and studies of habitat selection: problem, red herring, or opportunity? Pbilosophical Transactions of the Royal Society B: Biological Sciences 365:2233-2244 doi: 10.1098/rstb.2010.0079

Fukuda S, Hiramatsu K (2008) Prediction ability and sensitivity of artificial intelligence-based habitat preference models for predicting spatial distribution of Japanese medaka (Oryzias latipes). Ecological Modelling 215(4):301-313 doi: 10.1016/j.ecolmodel.2008.03.022

Horne JS, Garton EO, Rachlow JL (2008) A synoptic model of animal space use: simultaneous estimation of home range, habitat selection, and inter/intra-specific relationships. Ecological Modelling 214:338-348 doi: 10.1016/j.ecolmodel.2008.02.042

Keating KA, Cherry S (2004). Use and interpretation of logistic regression in habitat selection studies. Journal of Wildlife Management 68:774-789 doi:10.2193/0022541X(2004)068[0774:UAIOLR]2.0.CO;2

Lele SR (2009) A new method for estimation of resource selection probability function. Journal of Wildlife Management 73:122-127 doi: 10.2193/2007-535

Manly BFJ, McDonald LL, Thomas DL, McDonald TL, Erickson WP (2002) Resource selection by animals: statistical design and analysis for field studies. 2nd edn. The Netherlands: Kluwer Academic, Dordrecht

Montenegro J, Acosta A (2008) HaviStat $@$ v1.0 Aplicación para evaluar uso y preferencia de habitat. Pan-American Journal of Aquatic Sciences 3(2):II-IV

Nielsen SE, Shafer AB, Boyce MS, Stenhouse GB (2013) Does learning or instinct shape habitat selection? PloS One 8(1):e53721 doi: 10.1371/journal.pone.0053721

Rhodes JR, McAlpine CA, Lunney D, Possingham HP (2005) A spatially explicit habitat selection model incorporating home range behavior. Ecology 86:1199_ 1205 doi: 10.1371/journal.pone.0064656 
Vidus-Rosin A, Meriggi A, Cardarelli E, Serrano-Perez S, Mariani MC, et al. (2011). Habitat overlap between sympatric European hares (Lepus europaeus) and Eastern cottontails (Sylvilagus floridanus) in northern Italy. Acta Theriologica 56(1):53-61 doi: 10.1007/s13364-010-0005-x

HaviStat@ v2.2: Aplicación para estimar la preferencia por hábitat y recursos

Resumen. HaviStat@ v2.2 está disponible en español e Inglés. En esta versión los errores y recomendaciones reportados para la versión v1.0 fueron corregidos e implementados. HaviStat(C) permite a los usuarios realizar los procedimientos matemáticos, estadísticos y gráficos para inferir de forma preliminar uso, selección and preferencia por hábitat/recursos, y estimar la amplitud de nicho de las especies. En esta nueva versión se incluyen diagramas radiales, 22 índices and 3 intervalos de confianza para evaluar preferencia animal, y 8 índices para estimar amplitud de nicho también están disponibles.

Palabras clave: hábitat; preferencia; HaviStat $\mathrm{C}$; índices; intervalos de confianza.
HaviStat $\odot$ v2.2: Aplicativo para estimar a preferência em habitats e recursos

Resumo. HaviStat@ $\bigcirc 2.2$ está disponível em espanhol e inglês. Nesta versão os erros e as recomendações referenciados na versão v1.0 foram corrigidos e implementados. HaviStat(C) permite aos usuários realizar os procedimentos matemáticos, estatísticos e gráficos para inferir de forma preliminar o uso, seleção e preferência por hábitat/recursos e estimar a amplitude do nicho das espécies. Nesta nova versão, estão disponíveis, diagramas radiais, 22 índices e 3 intervalos de confiança para avaliar a preferencia animal, e 8 índices para estimar a amplitude do nicho.

Palavras-chave: habitat; preferência; HaviStat $($, índices; intervalos de confiança. 